\title{
A pumped thermal energy storage cycle with capacity for concentrated solar power integration
}

\author{
Pau Farres-Antunez \\ Department of Engineering \\ University of Cambridge \\ Cambridge, UK \\ pf298@cam.ac.uk
}

\author{
Joshua D. McTigue \\ National Renewable Energy Laboratory \\ Golden, CO, USA \\ JoshuaDominic.McTigue@nrel.gov
}

\author{
Alexander J. White \\ Department of Engineering \\ University of Cambridge \\ Cambridge, UK \\ ajw36@cam.ac.uk
}

\begin{abstract}
Pumped thermal energy storage (PTES) is a gridscale energy management technology that stores electricity in the form of thermal energy. A number of PTES systems have been proposed using different thermodynamic cycles, including a variant based on a regenerated Brayton cycle that stores the thermal energy in liquid storage media (such as molten salts) via heat exchangers. This has several advantages, including the possibility to consider hybrid "solar-PTES" systems employing technology developed by the concentrated solar power (CSP) industry. Such a hybrid system could charge the same hot stores using either solar energy or off-peak electricity (e.g. from nearby wind farms), increasing the capacity factor of the plant while employing the same heat engine during discharge.

In this paper, two different configurations of solar-PTES systems are proposed and studied numerically: (i) a configuration in which an existing CSP plant is retrofitted with a Brayton heat pump, and (ii) a configuration in which a new hybrid plant uses the Brayton cycle both for charge and discharge. In both cases, the need to absorb and reject heat at conditions close to ambient temperature requires the Brayton cycle to incorporate intercooled stages at the cold side of the cycle. On the other hand, the intercooling process increases the minimum temperature of the cold stores, meaning that widely available and nonflammable antifreeze solutions (such as water-ethylene glycol) may be used as the cold storage medium.
\end{abstract}

Index Terms-pumped thermal energy storage, concentrated solar power, thermodynamic cycle analysis, heat exchangers, energy efficiency

\section{INTRODUCTION}

Efforts to reduce greenhouse gas emissions and improve security of energy supply are driving the large-scale deployment of renewable energy generation. Renewable power plants accounted for more than $50 \%$ of all new installed power capacity between 2010 and 2016 worldwide, and this value is expected to continue to increase in the following decades [1]. The fluctuating nature of wind and solar energy constitutes a challenge for the power network, but large-scale storage together with other control strategies, such as grid interconnection and demand response - can mitigate the effects of such fluctuations [2]-[4].

Pumped thermal energy storage (PTES) is a grid-scale energy management technology that enjoys geographical independence together with a predicted low cost of energy capacity. The technology shares some important similarities with concentrated solar power (CSP), because the energy is stored in the form of high grade thermal energy and energy conversions occur via thermodynamic cycles.

This paper explores the possibility of integrating PTES with CSP to create 'solar-PTES' hybrid plants, which fall under the category of generation-integrated energy storage (GIES) systems, capable of both producing and storing electricity. After presenting brief reviews on the current development of both PTES and CSP, the paper explains the motivation behind such hybrid plants and presents the layout of two proposed configurations, the performance of which is studied numerically.

\section{A. PTES overview}

PTES stores electricity in the form of thermal exergy. During charge, a heat pump transfers thermal energy from a cold reservoir to a hot reservoir, creating a thermal potential between the two. During discharge, a heat engine is operated to recover the energy stored. The reservoirs are insulated to minimise losses during the storage period, although leakage losses are normally unimportant for large systems.

Thermal storage materials provide high storage densities, are cheap and abundant and thus well suited for large-scale applications. The thermal energy may be stored as sensible or latent heat, and in some cases the environment may also be employed as a heat source or sink, substituting one of the reservoirs. While the ideal thermodynamic efficiency of PTES is $100 \%$, the system is affected by several loss mechanisms, such as those occurring during the compression, expansion and heat transfer processes that drive the heat pump and heat engine cycles, and round-trip efficiencies are normally predicted in the range $50-70 \%$. Ongoing research is focused on reducing such losses through optimisation of components and cycle operating conditions, and reducing system costs.

The technology has received growing attention during the last decade, with a number of universities and companies proposing different variants of the same principle. These can be broadly divided in four groups depending on the cycle that they are based on, namely:

1) Brayton cycles

2) Rankine (or Organic Rankine) cycles

3) Transcritical cycles

4) Liquid air cycles 
Considering the purpose and scope of this paper, the discussion is limited here to a brief review on Brayton PTES systems, which are particularly suited for integration with CSP plants due to their ability to operate at high temperatures. However, the reader is referred to [5]-[7] where one can find extensive information about the other PTES variants.

Brayton PTES systems using argon as the working fluid were first proposed by Desrues et al. [8] (using turbomachinery) and Howes [9] (using reciprocating devices). In both cases, the working fluid always remains in the gas phase, and energy is stored in the form of sensible heat. Simple cycle analysis of these systems shows that they are particularly susceptible to compression and expansion losses because of the low work ratios ${ }^{1}$ inherent to the Brayton cycle [10]. The systems use solid storage media such as packed beds or matrices of refractory materials. Argon (or another monatomic gas) is preferred to air because a given temperature ratio can be achieved with a smaller pressure ratio; this is advantageous to reduce the cost of the storage tanks, which need to withstand the same pressure as the working fluid [11].

Packed beds of solid particles are advantageous because the filling materials are cheap, can be operated over wide temperature ranges and present a large surface areas for heat transfer. On the other hand, the spreading of the thermal fronts (which propagate along the tanks as the system charges and discharges) makes the operation of the system relatively complex, limits the energy density of the tanks and increases self-discharge losses. Analyses of these effects and numerical optimisation of packed beds, including the analysis of segmented packed beds, have been presented by White and McTigue et al. [11]-[16].

Isentropic Ltd. developed and built the first demonstration plant of Brayton PTES. The $150 \mathrm{~kW}_{\mathrm{e}} / 600 \mathrm{kWh}_{\mathrm{e}}$ plant, based on the system described in [9], is now owned and is being tested by Newcastle University [17]. An economic analysis of the system has been presented by Smallbone et al. [18], claiming that it can achieve costs per unit power and costs per unit energy which are comparable to PHS and CAES.

Brayton PTES cycles may also use liquid storage media and gas-to-liquid heat exchangers instead of solid (direct heat exchange) reservoirs, as proposed by Laughlin [19] and by Farres-Antunez [20]-[23]. Doing so allows the gas circuit to be pressurised (thereby increasing power density) whilst keeping the reservoirs at ambient pressure (thereby reducing their cost). Each storage tank is also kept at a single temperature, thus reducing self-discharge losses. As shown in Fig. 1, a regenerative heat exchanger may be incorporated into the cycle in order to adapt cycle temperatures to suit different liquid storage media (which have more limited temperature ranges than most solid materials). Regeneration also has benefits in terms of efficiency, as it increases the work ratio. Malta Inc. is currently working on the development of a $10 \mathrm{MW}_{\mathrm{e}} /$ $80 \mathrm{MWh}_{\mathrm{e}}$ system based on such regenerated scheme [24].

\footnotetext{
${ }^{1}$ For a heat engine, the work ratio is defined as the expansion work output over compression work input, while the opposite is used for a heat pump.
}

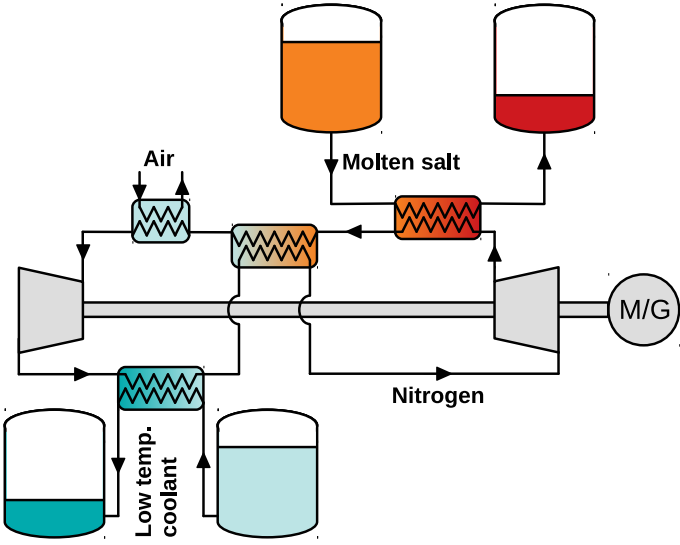

Fig. 1: Plant layout of a Brayton PTES system with liquid reservoirs and a gas-gas regenerator. Arrows indicate direction of flow during charge. During discharge the flows are reversed and another set of turbomachines is required (unless reciprocating devices are employed, in which case the same machines may be run backwards). Figure adapted from [23].

\section{B. CSP overview}

Concentrating Solar Power (CSP) is a category of solar thermal energy in which solar radiation is concentrated in order to generate high temperature fluid which may be used to drive a heat engine and generate electricity. Since its inception in the 1980s, $4.8 \mathrm{GW}_{\mathrm{e}}$ of CSP has been deployed as of 2017. Deployment of CSP is anticipated to continue with a further $8.5 \mathrm{GW}_{\mathrm{e}}$ under construction or development [26].

Sunlight is concentrated by reflection onto a receiver, and four commonly accepted methods are illustrated in Fig. 2. Parabolic trough collectors (PTC) are the most commercially widespread CSP technology, and are line-focus solutions that concentrate radiation onto a linear receiver. PTCs typically use thermal oils as the heat transfer fluid (HTF) and therefore tend to be limited to temperatures below $390^{\circ} \mathrm{C}$. Linear Fresnel reflectors (LFR) approximate the shape of a parabolic trough, and have so far not been widely deployed despite potentially being cheaper and simpler to manufacture.

Point-focus technologies can achieve higher concentration ratios, and therefore temperatures, than PTCs and LFRs [27]. These technologies include central receiver towers and parabolic dishes, and using conventional nitrate molten salts can operate up to $565^{\circ} \mathrm{C}$. Central power towers are being commercially deployed, with around $5.4 \mathrm{GW}_{\mathrm{e}}$ currently under construction or development.

Thermal energy storage enables CSP to be flexible and dispatchable, and is a feature of nearly all new CSP plants. By decoupling supply and demand of energy, thermal storage can buffer power output in the event of cloud cover, increase the capacity factor, and enable the dispatch of solar energy at higher value times. The vast majority of operational CSP plants use nitrate molten salts, although some systems use steam or concrete as the storage media [28].

Conventional CSP technologies convert the HTF thermal 


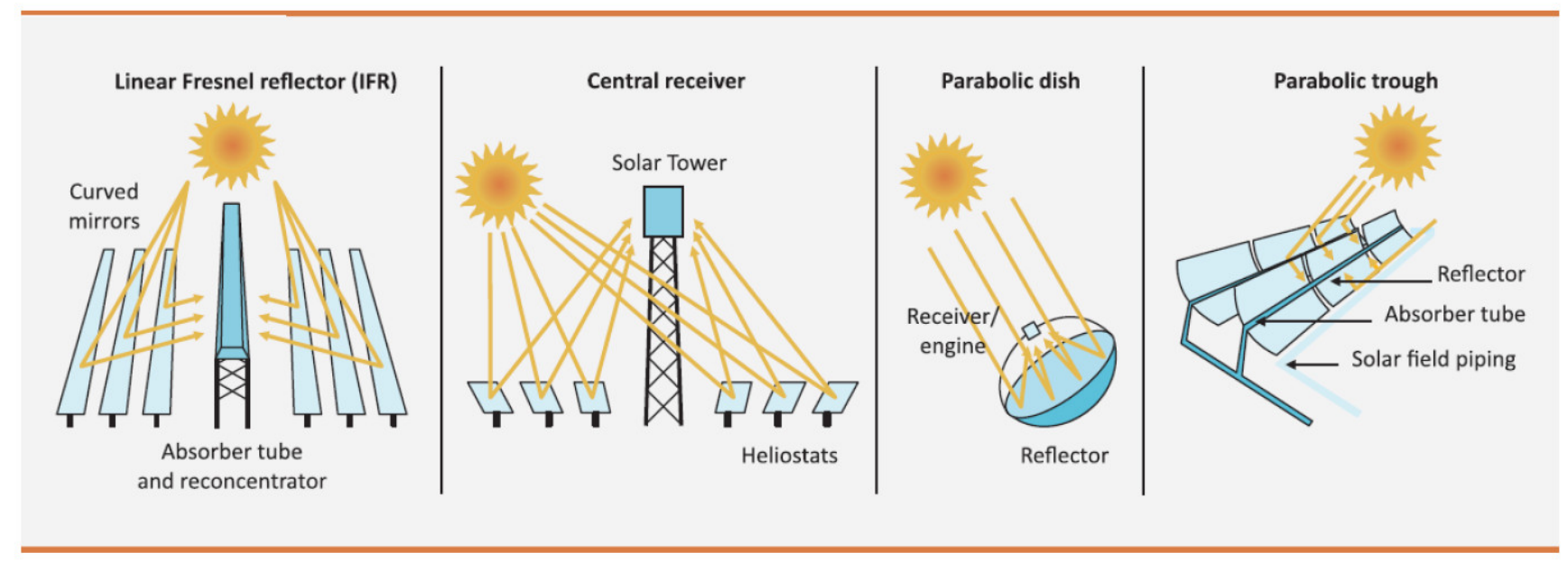

Fig. 2: Four methods of concentrating solar radiation on to a receiver. Figure from [25]: IEA (2014), Technology Roadmap: Solar Thermal Electricity. All rights reserved.

energy to electricity in a steam turbine, with efficiencies of up to $40-42 \%$ [29], [30] for power towers. There has been growing interest in an alternative power cycle based on supercritical carbon dioxide. This real-gas Brayton cycle can potentially achieve higher efficiencies than conventional steam Rankine cycles, with U.S. Department of Energy (DOE) targets of $50 \%$ at temperatures over $700{ }^{\circ} \mathrm{C}$ [31]. The high density of carbon dioxide leads to compact machinery that has potentially lower cost than machines with higher volumetric flows. Reaching these high temperatures requires developments in new thermal storage materials and containments, with chloride molten salts and particle storage being active areas of research and development [31]. Ideal-gas Brayton cycles have also been considered for CSP applications, although these cycles typically require high temperatures $\left(1200^{\circ} \mathrm{C}\right)$ for efficient operation [32]. As a result, hybridisation with a fossil fuel combustor have been suggested [29]. In this article, heat engines of interest are conventional steam Rankine cycles, and air-Brayton cycles that use sub-ambient cold storage and intercooling to achieve acceptable efficiencies.

\section{Motivation for solar-PTES systems}

PTES and CSP systems use similar power cycles and thermal storage, and PTES development may be accelerated by leveraging knowledge from the CSP industry. Co-location, or the direct integration of PTES with CSP cycles, may provide further benefits, either in terms of performance or in operational and maintenance (O\&M) costs.

While thermal storage at a CSP plant enables supply to be decoupled from demand, the dispatch of electricity is still ultimately dependent on solar availability. This is particularly notable during the winter, with Fig. 3 indicating that solar power available between November and January is around half the power available between June and August in Seville - an area of Spain where many CSP plants have been deployed. Not only is electricity dispatch reduced in the winter, with the power cycle operating at part load, but the thermal storage is not used to its full extent. This spare capacity could be exploited by adding a PTES heat pump that could 'top-up' the thermal storage. In this scenario, the CSP plant could be relied upon to provide electricity whenever required - provided that lower value electricity has been stored.

Co-locating a CSP plant with a heat pump could potentially enable the deployment of CSP systems in regions previously considered to have an insufficient solar resource, such as some coastal areas. The power density of wind and solar for Montpellier, France is shown in Fig. 4. Like Seville, the solar resource declines significantly in the winter, when wind energy is most abundant. Excess wind (possibly from off-shore wind farms) could be stored as heat at a CSP-PTES plant using the spare capacity of the thermal storage.

Retrofitting existing CSP plants with a PTES heat pump would enable PTES concepts to be demonstrated at lower cost, since the hot storage and discharging cycle are already installed. A system of this type can provide both power generation and energy storage services. Since several components are used in both systems, the operational and maintenance costs may be reduced compared to two separate installations. The layout of retrofitted CSP plants is discussed in section II-A.

However, using a Brayton charging cycle and a Rankine discharging cycle may not be the most effective combination, since PTES systems tend to be more efficient when both cycles are of the same type, due to a better match of operating temperature ranges and amount of thermal energy stored in the hot and cold tanks. A potentially more efficient integration may be obtained by designing a CSP-PTES plant where the Brayton cycle is used during both charge and discharge, as described in section II-B. 


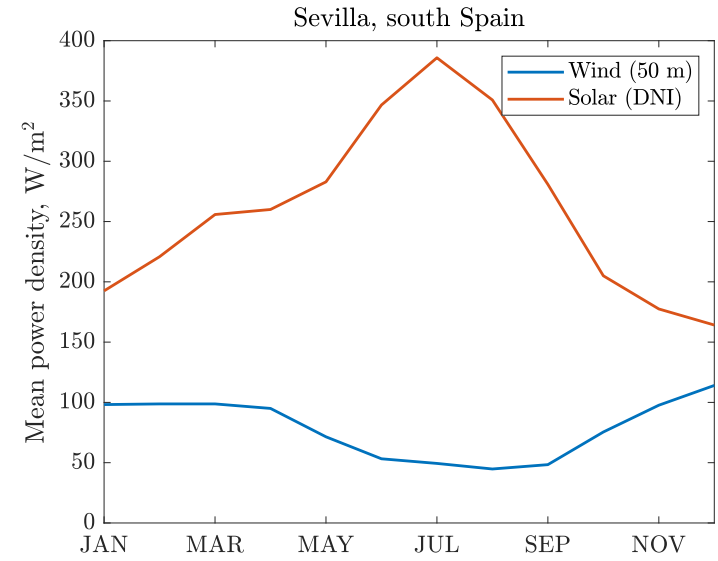

Fig. 3: Power density of wind and solar in Seville, Spain. Data from [33].

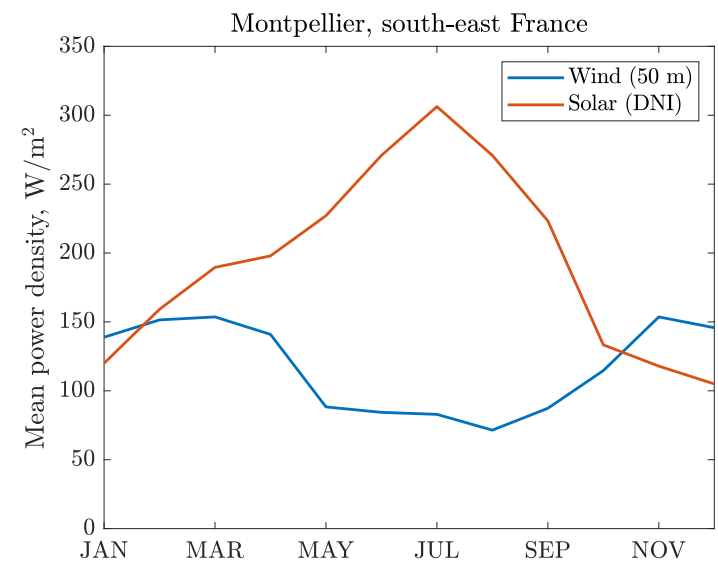

Fig. 4: Power density of wind and solar in Montpellier, France. Data from [33].

\section{SyStem LAYOUT}

\section{A. CSP retrofit}

Retrofitting an existing thermal power plant with a heat pump and thermal stores was recently investigated in a study by Vinnemeier et al. [34]. The concept is appealing because it results in a hybrid plant able to operate using either the original heat source (e.g. a fossil fuel) or the heat generated by the heat pump during periods of off-peak electrical demand. If the purchased electricity comes from renewable sources, such hybrid plants would represent a cost-effective way to reduce carbon emissions while ensuring security of supply: the plants could mainly operate from renewable electricity (using the thermal stores to balance power fluctuations) and use the combustible source only as a backup during long periods of low renewable generation.

Vinnemeier et al. investigated this concept by modelling the performance of transcritical and supercritical (i.e. Brayton) heat pumps operating at temperatures compatible with steam power plants [34]. The authors found that the heat pumps were generally less susceptible to irreversibility when operating at higher temperatures (e.g. delivering heat between $300^{\circ} \mathrm{C}$

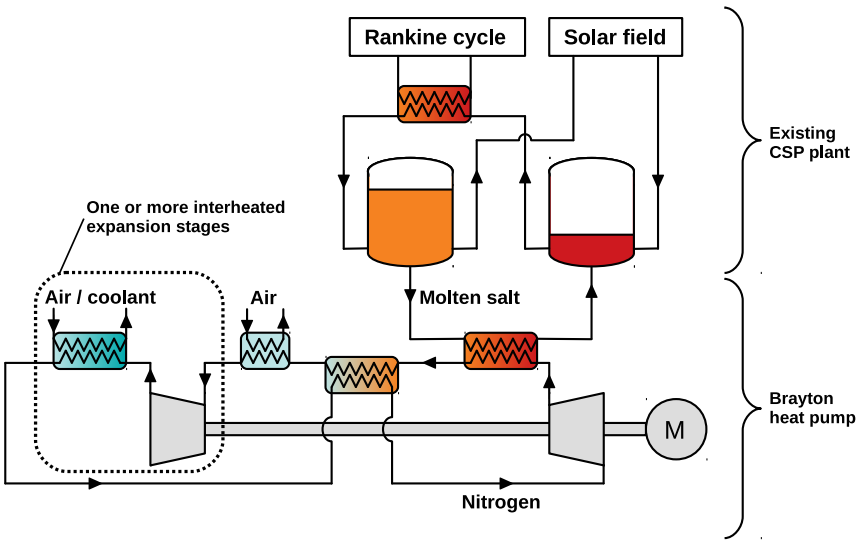

Fig. 5: Proposed layout of a solar-PTES plant in which an existing CSP plant is retrofitted with a Brayton heat pump.

and $600^{\circ} \mathrm{C}$ ), and that in the high-temperature regime the Brayton designs reached similar or superior performance to the transcritical cycles.

When considering the different kinds of thermal power plant that could be retrofitted in such a way, most CSP plants have the advantage of already including large thermal stores in the original design, thus only requiring the addition of the heat pump. The layout of the proposed hybrid plant is shown in Fig. 5. From right to left, the Brayton heat pump consists of: 1) a compressor, 2) a heat exchanger to transfer heat to the molten salt tanks, 3) a regenerator, 4) a heat exchanger to reject low-grade heat to the environment, 5) an expander (i.e. a turbine) and 6) a heat exchanger where cold thermal energy is either stored or rejected to the environment. Noticeably, the heat pump may consist of one or more interheated expansion stages, which, as shown later, has a significant impact on the cycle's performance.

The working fluid of the Brayton cycle is assumed to be pure nitrogen, rather than air, because nitrogen is free from moisture and pollutants. As mentioned above, argon is preferred in PTES systems that employ solid stores with direct heat transfer because it requires low pressure ratios for a given temperature ratio. However, PTES systems that employ heat exchangers can contain much higher pressures and in this case nitrogen is preferred for its superior heat transfer properties. Furthermore, the heat pump cycle is assumed to be significantly pressurised, such that the high pressure line is at $100 \mathrm{bar}$, and the low pressure line is adapted according to the desired pressure ratio (which is determined by the temperature range of the molten salt tanks). Pressurising the working fluid increases the power density of the cycle and is expected to result into more compact (and cheaper) compressors and expanders. The value of $100 \mathrm{bar}$ is selected for it being high enough to result in significant power density gains while staying well below the maximum pressures for which there are successful technological experiences in commercial power plants (e.g. supercritical steam cycle plants operating at above 250 bar [29]). 


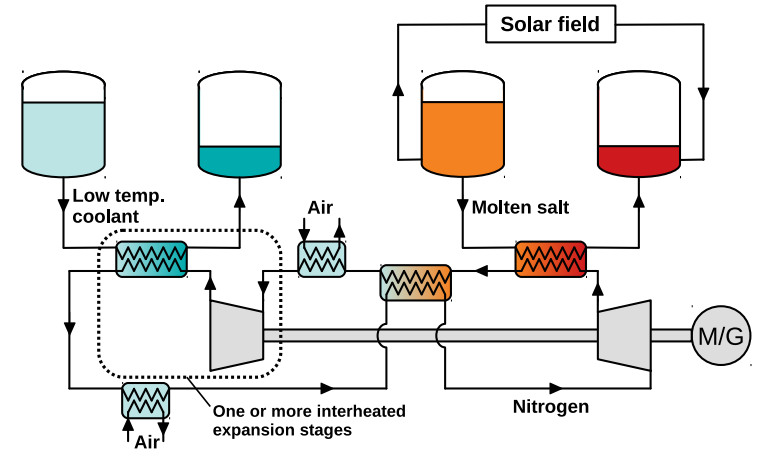

Fig. 6: Proposed layout of a new solar-PTES plant. Arrows indicate direction of flow during charge. During discharge the flows are reversed and another set of turbomachines is required (unless reciprocating devices are employed, in which case the same machines may be run backwards).

\section{B. New hybrid plant}

An alternative to retrofitting an existing CSP plant is to design the whole new hybrid plant from the beginning. This enables the charge and discharge cycles to be based on the Brayton cycle, which permits an easy and effective utilisation of the cold thermal energy supplied by the heat pump during charge.

The layout of the proposed hybrid plant is shown in Fig. 6 . The system employs a recuperated Brayton PTES cycle during charge and discharge. The hot store (which uses molten salts) operates at the same temperature range as the CSP solar field, while the cold store may use various low temperature coolants depending on the minimum temperatures required, which depends on the number of interheated expansion stages. Noticeably, the heat pump charges both the hot and the cold stores, but the solar field charges only the hot store. If the cold stores have been charged, the heat engine can use them to pre-cool the air entering the compressor, which reduces compression work during discharge. If the cold sores are not charged, the heat exchanger that connects them to the heat engine is simply bypassed.

As in the CSP-retrofit scheme, nitrogen is selected as working fluid and the cycle is assumed to be pressurised. During charge, a top pressure of $100 \mathrm{bar}$ is selected, and the bottom pressure is determined by the selected temperature range of the hot stores. During discharge, the bottom pressure is kept the same and the top pressure is optimised for maximum efficiency.

\section{NUMERICAL MODELLING}

Straightforward 'design point' cycle calculations were undertaken using fixed values of component performance parameters such as compression and expansion efficiencies, fractional pressure losses and heat exchanger effectiveness.

The numerical model employed is essentially an adaptation of the Brayton-PTES code described in [23], which was validated against analytical results in the appropriate limits (i.e. ideal gas, constant heat capacity fluids, etc.). As described in [23], the cycle model was implemented in Matlab and thermodynamic properties were evaluated using the CoolProp library [35]. The model assumes steady state operation and ensures 'cycle sustainability' (i.e. the conditions of the storage tanks at the end of discharge are the same as those at the beginning of charge).

When interpreting the results of the model, it should be noted that the following sources of loss were neglected:

1) Storage (i.e., heat leakage) losses from the reservoirs.

2) Mechanical and electrical conversion losses.

3) Parasitic losses, such as the pumping load for the liquid storage media and the fan load to drive the atmospheric air through the external heat exchangers.

The main assumptions on component performances and operating conditions are summarised in Table I.

TABLE I: Component performances and operating conditions.

(a) Fixed parameters.

\begin{tabular}{lcc}
\hline Parameter & Unit & Value \\
\hline \hline Ambient temperature, $T_{0}$ & ${ }^{\circ} \mathrm{C}$ & 27 \\
\hline Top temperature molten salts, $T_{\text {top }}$ & ${ }^{\circ} \mathrm{C}$ & 565 \\
\hline Top pressure working fluid (charge), $p_{\max }$ & bar & 100 \\
\hline Compressor/expander polytropic efficiency, $\eta$ & - & 0.90 \\
\hline Heat exchanger effectiveness, $\epsilon$ & - & 0.97 \\
\hline Heat exchanger pressure loss, $\Delta p / p$ & - & 0.01 \\
\hline
\end{tabular}

(b) Variable parameters

\begin{tabular}{lcc}
\hline Parameter & Unit & Value \\
\hline \hline Bottom temperature molten salts, $T_{\text {bot }}$ & ${ }^{\circ} \mathrm{C}$ & {$[250-500]$} \\
\hline Number of interheated stages, $N_{\text {stages }}$ & - & {$[1-3]$} \\
\hline
\end{tabular}

\section{A. Compressors and expanders}

In order to ensure a valid comparison when studying the effect of different pressure ratios on the overall performance, compressors and expanders are modelled by a polytropic (rather than isentropic) efficiency [36]. This is defined in the usual fashion as an infinitesimal stage efficiency. Thus:

$$
\begin{aligned}
\eta_{\mathrm{c}} & \equiv \frac{\delta w_{\mathrm{c}, \mathrm{rev}}}{\delta w_{\mathrm{c}}}=\frac{v \mathrm{~d} p}{\mathrm{~d} h} \\
\eta_{\mathrm{e}} & \equiv \frac{\delta w_{\mathrm{e}}}{\delta w_{\mathrm{e}, \mathrm{rev}}}=\frac{\mathrm{d} h}{v \mathrm{~d} p}
\end{aligned}
$$

These expressions are then integrated at constant efficiency to obtain the total change in enthalpy for specified inlet conditions and outlet pressure. Baseline calculations assume a polytropic efficiency of $90 \%$ for all compressors and expanders. 


\section{B. Heat exchangers}

The effectiveness of a heat exchanger is defined as [37]:

$$
\epsilon=\frac{\dot{m} \Delta h}{\dot{Q}_{\max }}
$$

where $\dot{Q}_{\max }$ represents the maximum possible heat transfer rate, i.e. that of an infinitely large heat exchanger. For a given set of inlet conditions (considering real fluid properties), $\dot{Q}_{\max }$ is found by iteration and corresponds to the situation in which the pinch-point temperature difference is $0{ }^{\circ} \mathrm{C}$. Baseline calculations assume $97 \%$ effectiveness, which is an ambitious value but has been shown to be feasible in the context of highperformance, counter-flow, compact heat exchangers [38]. A fractional pressure loss $(\Delta p / p)$ of $1 \%$ is also specified for all heat exchangers.

\section{Performance indices and second law analysis}

Several performance indices, such as heat pump coefficient of performance (COP), heat engine efficiency, exergetic (or round-trip) efficiency, power density and energy density are used to assess the performance of the different subsystems of the solar-PTES plant. The definitions of these well-established indices can be found in the literature, e.g. see [39].

Apart from computing heat and work flows along the cycle, the model also computes entropy generation in each component, which allows the distribution of exergetic losses to be determined. Results from the second law analysis accurately match the results from the first law analysis on the overall energy and exergetic balances.

\section{RESUlts AND Discussion}

\section{A. CSP retrofit}

In the CSP retrofit scheme, a Brayton heat pump absorbs heat from the environment and delivers heat to the molten salt tanks. The molten salt tanks can be charged either by the heat pump or the solar field, and they are discharged by the existing Rankine cycle.

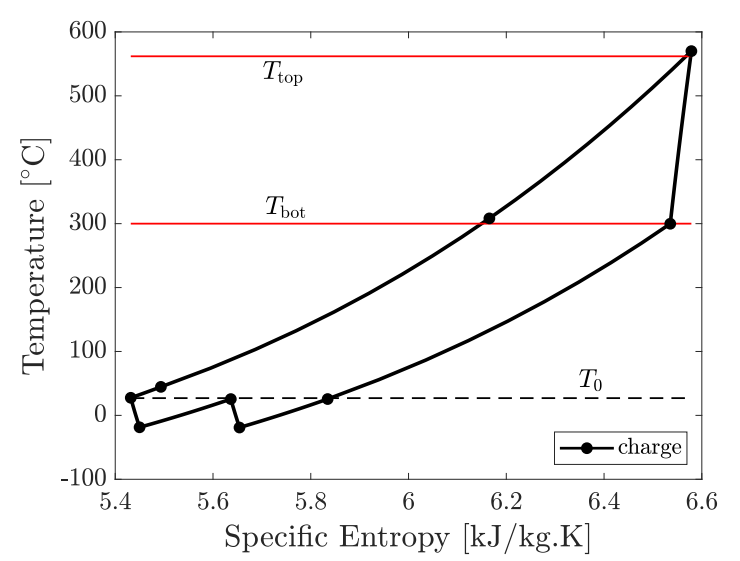

Fig. 7: T-s diagram of the Brayton heat pump displaying two interheated expansions $\left(\mathrm{N}_{\text {stages }}=2\right)$.

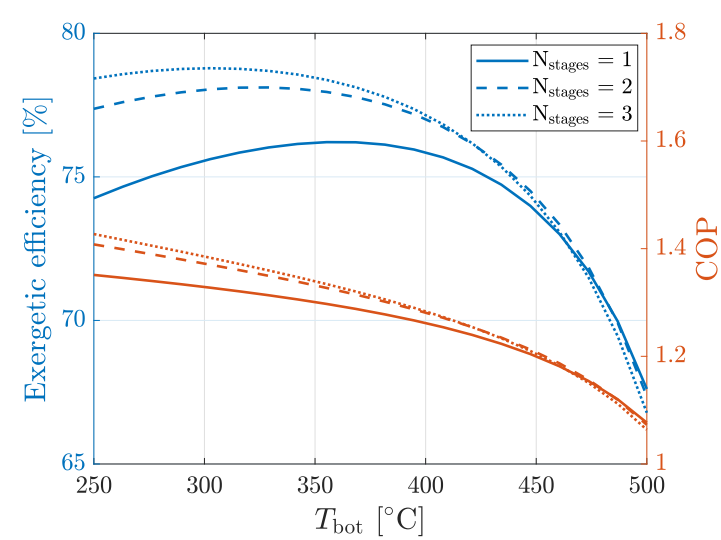

Fig. 8: Exergetic efficiency and COP as a function of $T_{\text {bot }}$ and $N_{\text {stages }} . T_{\text {top }}$ is kept constant at $565{ }^{\circ} \mathrm{C}$.

A T-s diagram of the modelled heat pump cycle is shown in Fig. 7. In the case shown, the cycle delivers heat between $T_{\text {bot }}=300^{\circ} \mathrm{C}$ and $T_{\text {top }}=565^{\circ} \mathrm{C}$, while the environment temperature is $T_{0}=27^{\circ} \mathrm{C}$. The cycle in the graph displays two interheated expansions $\left(\mathrm{N}_{\text {stages }}=2\right)$. For a given pressure ratio, increasing $N_{\text {stages }}$ increases the overall expander work (and makes the heat to be absorbed at temperatures closer to $T_{0}$, meaning that there is a lower exergy loss), which improves the performance of the heat pump.

The COP and exergetic efficiency ${ }^{2}$ of the heat pump are shown in Figure 8 as a function of $T_{\mathrm{bot}}$ and $N_{\text {stages. }}$. The COP decreases as $T_{\text {bot }}$ increases, as one would expected from any heat pump when delivering heat at higher temperatures. There is, however, a significant advantage in increasing $\mathrm{N}_{\text {stages }}$ from 1 to 2 , while the advantage of having $\mathrm{N}_{\text {stages }}=3$ is more moderate.

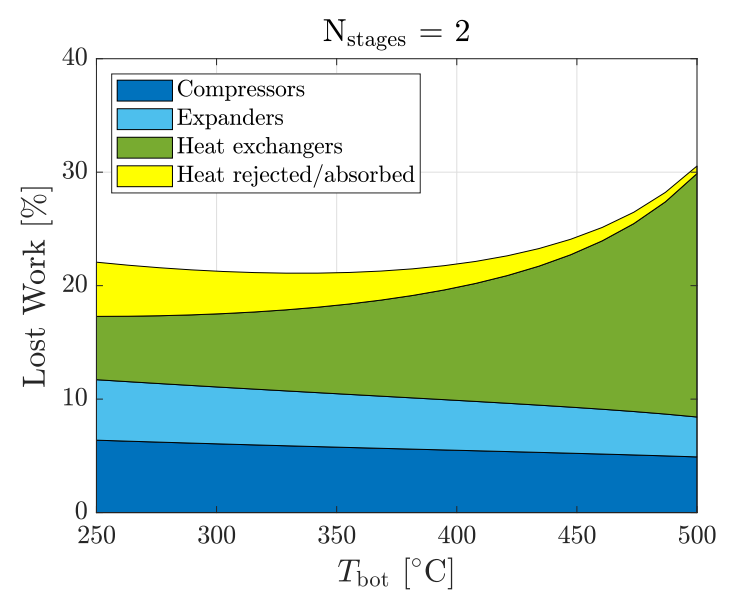

Fig. 9: Variation of exergetic losses in the Brayton heat pump as a function of $T_{\text {bot }} . T_{\text {top }}$ is kept constant at $565^{\circ} \mathrm{C}$. $\mathrm{N}_{\text {stages }}=2$.

The exergetic efficiency also increases with $\mathrm{N}_{\text {stages }}$, while

\footnotetext{
${ }^{2}$ The exergetic efficiency of the heat pump is computed by dividing the thermal exergy gained by the hot stores by the net work input of the heat pump.
} 
it first increases but then decreases with $T_{\text {bot }}$. This optimum can be explained with reference to Fig. 9, which shows how the distribution of exergetic losses varies with temperature. As $T_{\text {bot }}$ increases, the pressure ratio decreases (because $T_{\text {top }}$ is fixed). The compression process occurs at higher temperatures, which improves the work ratio and decreases the losses associated with compression and expansion. The lower pressure ratio also means that heat is absorbed, on average, at temperatures closer to $T_{0}$, which reduces the irreversibility of the heat absorption process (i.e. similarly to what happens when increasing $\mathrm{N}_{\text {stages }}$ ). On the other hand, as the pressure ratio decreases the net work input also decreases, which makes the cycle much more susceptible to the pressure and heat transfer losses in the regenerator and all other heat exchangers.

A summary of the results for an example configuration is shown in Table II, where a value of $T_{\text {bot }}=300{ }^{\circ} \mathrm{C}$ is selected to maximise the temperature range (and energy density) of the hot tanks while staying close to the exergetic optimum of the heat pump. An efficiency of $40 \%$ is estimated for the Rankine cycle, based on reported efficiencies of CSP plants operating at similar top temperatures [29]. The round-trip efficiency of the hybrid plan is then simply obtained by multiplying the Rankine cycle efficiency with the COP of the Brayton heat pump (1.37 according to the results of the numerical model). The result suggests that round-trip efficiencies close to $55 \%$ should be achievable for solar-PTES systems based on the CSP-retrofit scheme.

TABLE II: CSP retrofit. Summary results of an example configuration using $T_{\text {top }}=565^{\circ} \mathrm{C}, T_{\text {bot }}=300^{\circ} \mathrm{C}$ and $\mathrm{N}_{\text {stages }}=2$.

\begin{tabular}{lcc}
\hline Parameter & Unit & Value \\
\hline \hline Heat pump COP & - & 1.37 \\
\hline Rankine cycle efficiency (estimate) & $\%$ & 40.0 \\
\hline Round-trip efficiency (estimate) & $\%$ & 54.8 \\
\hline Heat pump power density & $\mathrm{MW}_{\mathrm{e}} /\left(\mathrm{m}^{3} / \mathrm{s}\right)$ & 3.44 \\
\hline Energy density hot tanks & $\mathrm{kWh}_{\mathrm{e}} / \mathrm{m}^{3}$ & 80 \\
\hline
\end{tabular}

The current analysis assumes that the cold thermal energy delivered by the heat pump is rejected to the environment, but it could potentially be stored in cold thermal tanks and used to boost the efficiency of the Rankine cycle (which would reject heat at lower temperatures) during discharge. This will be investigated in a future study.

\section{B. New hybrid plant}

In the layout of the new hybrid plant, both the charge and discharge cycles are based on the Brayton cycle, as is normally the case for Brayton-PTES. The solar-PTES plant has both hot and cold stores and two different modes of operation: a PTES mode, where the hot and the cold storage tanks are charged and discharged via the Brayton cycle, and a CSP mode, where the hot stores are charged by the solar field and discharged via the Brayton cycle (but the cold stores are not used).

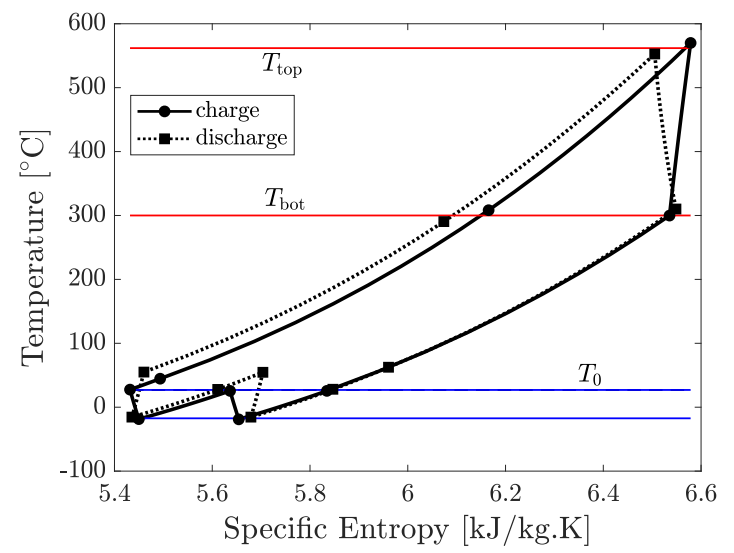

Fig. 10: T-s diagram of the PTES cycle.

Figure 10 shows the T-s diagram of the solar-PTES plant in PTES operation. The diagram shows an example with $\mathrm{N}_{\text {stages }}=2$ (i.e. two interheated expansions during charge, and the same number of intercooled compressions during discharge).

The round-trip efficiency of the PTES system, when operating at the optimal discharge pressure ratio, is shown in Fig. 11. The maximum efficiency is above $61 \%$ and thus exceeds the $\sim 55 \%$ round-trip efficiency value estimated for the CSP-retrofit plant in the previous section. However, the difference in efficiency will likely be reduced if the CSPretrofit plant were to incorporate cold storage tanks.

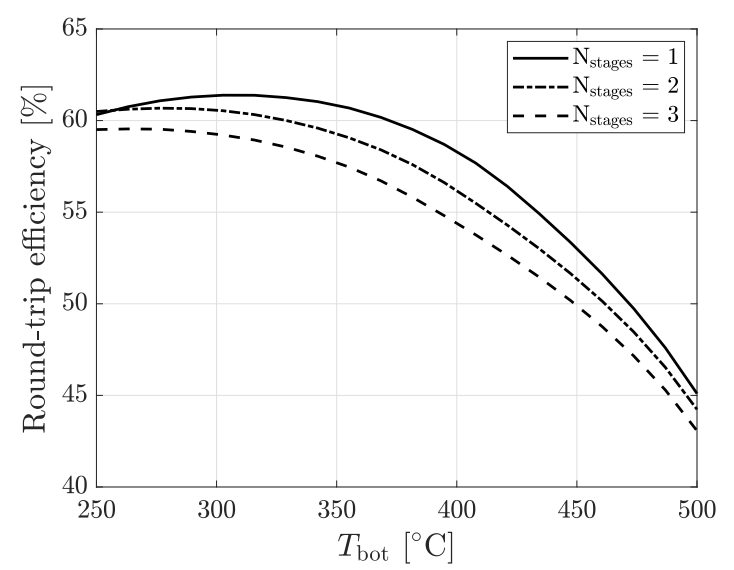

Fig. 11: Round-trip efficiency of the Brayton PTES system as a function of $T_{\text {bot }}$ and $\mathrm{N}_{\text {stages }} . T_{\text {top }}$ is kept constant at $565^{\circ} \mathrm{C}$.

The relationship between efficiency and $T_{\text {bot }}$ is similar to that seen in Fig. 8 for the heat pump, although the optimal temperature is displaced to lower values. On the other hand, the effect of varying $\mathrm{N}_{\text {stages }}$ is the opposite to before, since now the efficiency decreases as $\mathrm{N}_{\text {stages }}$ increases (although the effect is rather small, particularly at low values of $T_{\text {bot }}$ ). A higher value of $\mathrm{N}_{\text {stages }}$ decreases the work ratio and makes the cycle more susceptible to compression and expansion losses. Since the cold supplied by the heat pump is now stored in the 
cold thermal tanks and reused during discharge, there is no exergetic benefit in having interheated stages.

Increasing the number of stages, however, presents other advantages. Notably, the minimum temperature of the cycle is raised, meaning that coolants with higher freezing points can be used as storage media in the cold tanks. This is important because there are not many liquid materials which are suitable for this kind of application, and coolants with higher freezing points tend to be safer and/or more widely available. A non-exhaustive comparison of a few candidates is shown in Table III.

TABLE III: Low temperature coolants with potential use in thermal energy storage applications. Adapted from [23].

\begin{tabular}{|c|c|c|c|c|}
\hline Material & $\begin{array}{c}T_{\min } \\
{ }^{\circ} \mathrm{C}\end{array}$ & $\begin{array}{c}\text { Flash point } \\
{ }^{\circ} \mathrm{C}\end{array}$ & $\begin{array}{c}c_{p} \\
\mathrm{~kJ} / \mathrm{kg} \mathrm{K}\end{array}$ & $\begin{array}{c}\text { Cost } \\
\text { USD } / \mathrm{kg}\end{array}$ \\
\hline \hline Pentane & -130 & -50 & 2.04 & 1.4 \\
\hline Ethanol & -114 & 9 & 2.01 & 0.5 \\
\hline Methanol & -98 & 11 & 2.26 & 0.3 \\
\hline $\begin{array}{c}\text { MEG- } \mathrm{H}_{2} \mathrm{O} \\
(60-40 \mathrm{wt} \%)\end{array}$ & -50 & $>100$ & 3.03 & 0.5 \\
\hline
\end{tabular}

In a PTES system with a single expansion and no interheating (i.e. $N_{\text {stages }}=1$ ), as originally proposed for regenerated stand-alone PTES schemes, the turbine outlet can reach temperatures as low as $-80^{\circ} \mathrm{C}$ and below during charge, depending on the exact operating conditions. This would be too low for the most commonly found antifreeze materials, and less safe alternatives (which have flash points below or around ambient temperature), such as methanol, ethanol or pentane need to be used. On the other hand, setting $N_{\text {stages }}=2$ brings the minimum temperature up to $-40{ }^{\circ} \mathrm{C}$ and above, meaning that the ethylene glycol-water eutectic, among other common antifreeze materials, becomes a viable option.

A T-s diagram of the solar-PTES plant operating in CSP mode is shown in Fig. 12. In this case, the molten salts are charged by the solar field and the cold tanks remain empty, meaning that the Brayton heat engine has a higher compressor inlet temperature and a comparatively worse performance, due to the increased compressor work.

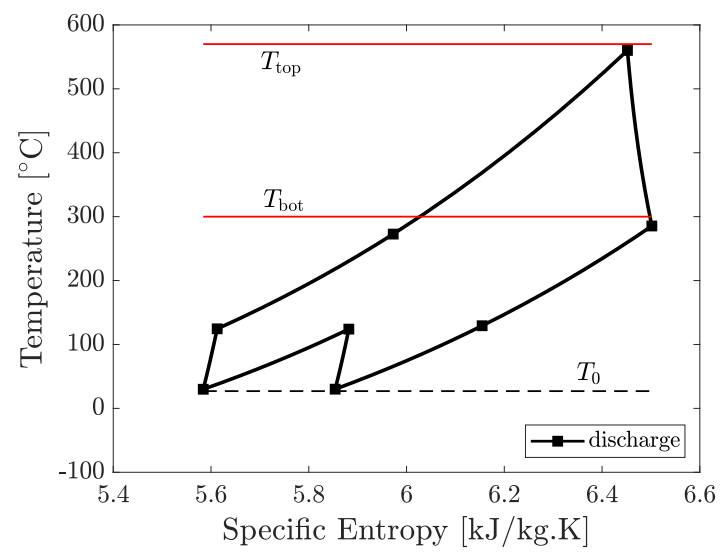

Fig. 12: T-s diagram of the Brayton heat engine, rejecting heat to the environment when the cold stores are empty.

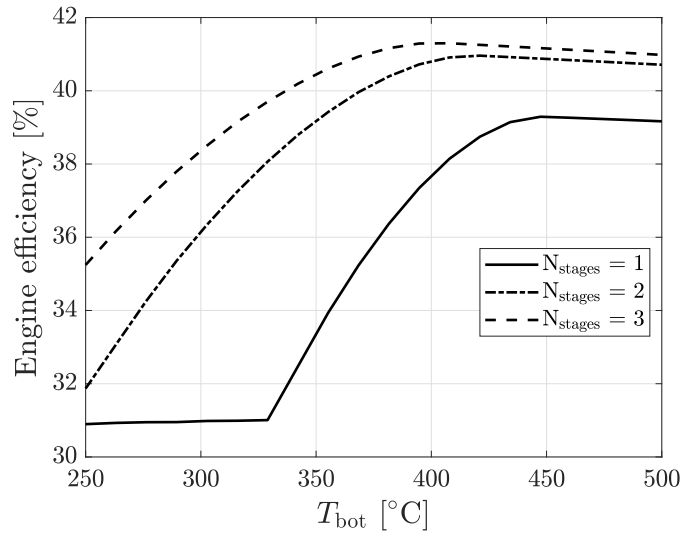

Fig. 13: Heat engine efficiency as a function of $T_{\text {bot }}$ and $\mathrm{N}_{\text {stages }} . T_{\text {top }}$ is kept constant at $565^{\circ} \mathrm{C}$.

The heat engine efficiency, as a function of $T_{\mathrm{bot}}$ and $\mathrm{N}_{\text {stages }}$, is shown in Fig. 13. Remarkably, the maximum efficiency exceeds $40 \%$, even though the top temperature of the cycle is 'only' $565{ }^{\circ} \mathrm{C}$ (a temperature within the normal range for modern Rankine cycles, but much lower than the temperatures normally encountered in Brayton cycles). Note that this value represents only a thermodynamic efficiency, since, as noted above, the 'external' sources of irreversibility (such as mechanical, electrical and parasitic losses) are not accounted for, and that the actual efficiency would be lower. Furthermore, the results are only as valid as the assumptions taken for the different component efficiencies (shown in Table I). While the specified compression/expansion efficiencies seem to be in line with state-of-the-art machinery, the (relatively high) heat exchanger effectivenesses assumed could potentially require surface areas which are too large (and expensive) for a power plant, and this aspect is going to be assessed in a future study. However, if the assumed component efficiencies prove to be feasible, the graph would suggest that intercooled and regenerated Brayton cycles could compete with Rankine cycles in power plants displaying top temperatures above $\sim 550^{\circ} \mathrm{C}$.

Figure 13 also shows that both increasing $T_{\text {bot }}$ and $\mathrm{N}_{\text {stages }}$ have significant positive impacts on the heat engine efficiency. The effect of the former should be expected for any heat engine, while the latter can be explained by noticing that more intercooled compression stages reduces the compression work and thus increases the net work.

The numerical model used to generate Fig. 13 always employs the optimal discharge pressure ratio which maximises the amount of work delivered during discharge for a given temperature range of the hot tanks. This optimum is found by iteration using a simple golden-search algorithm, as described in [23]. Since $T_{\text {top }}$ and $T_{0}$ are fixed, the optimal pressure ratio increases as $T_{\text {bot }}$ decreases, such that the heat engine can absorb the full thermal potential stored in the hot tanks. However, as the pressure ratio keeps increasing, there is a point when the outlet temperature of the compressor approaches the outlet temperature of the turbine. When this happens, the heat engine is no longer able to obtain a higher work output 
from further increasing the pressure ratio, at which point the operating conditions become independent of $T_{\text {bot }}$ (which explains the flat line at low $T_{\text {bot }}$ values for $\mathrm{N}_{\text {stages }}=1$ ).

Comparing Figures 11 and 13 it is evident that the optimal settings for PTES operation are different than those for CSP operation. The former favours small values of $\mathrm{N}_{\text {stages }}$ ( 1 or 2) and $T_{\text {bot }}$ (between $250^{\circ} \mathrm{C}$ and $320^{\circ} \mathrm{C}$ ), while the latter favours higher values of $\mathrm{N}_{\text {stages }}$ ( 2 or 3 ) and $T_{\text {bot }}$ (around $400{ }^{\circ} \mathrm{C}$ ). The choice will ultimately depend on the predicted weight of each system (e.g. which mode of operation is to be used most often in a particular plant), but an educated guess suggests that a likely compromise might be at around $\mathrm{N}_{\text {stages }}=2$ and $T_{\text {bot }} \simeq 350{ }^{\circ} \mathrm{C}$, since under those conditions the two modes of operation would still be running relatively close to their respective optimal points. A summary of the results under those specific conditions is shown in Table IV.

TABLE IV: New hybrid plant. Summary results of an example configuration using $T_{\text {top }}=565^{\circ} \mathrm{C}, T_{\text {bot }}=350{ }^{\circ} \mathrm{C}$ and $\mathrm{N}_{\text {stages }}=2$.

(a) PTES mode (i.e. charging hot and cold stores with Brayton heat pump, discharging with Brayton heat engine)

\begin{tabular}{lcc}
\hline Parameter & Unit & Value \\
\hline \hline Round-trip efficiency & $\%$ & 59.3 \\
\hline Power density (discharge) & $\mathrm{MW}_{\mathrm{e}} /\left(\mathrm{m}^{3} / \mathrm{s}\right)$ & 2.06 \\
\hline Energy density (hot and cold tanks) & $\mathrm{kWh}_{\mathrm{e}} / \mathrm{m}^{3}$ & 27.6 \\
\hline
\end{tabular}

(b) CSP mode (i.e. charging hot stores with solar field, discharging with Brayton heat engine).

\begin{tabular}{lcc}
\hline Parameter & Unit & Value \\
\hline \hline Heat engine efficiency & $\%$ & 39.2 \\
\hline Heat engine power density & $\mathrm{MW} /\left(\mathrm{m}^{3} / \mathrm{s}\right)$ & 1.88 \\
\hline Energy density (hot tanks only) & $\mathrm{kWh} / \mathrm{m}^{3}$ & 68.6 \\
\hline
\end{tabular}

\section{CONCLUSIONS AND FUTURE WORK}

Solar-PTES is presented as a new concept of a hybrid system that combines concentrated solar power (CSP) and pumped thermal energy storage (PTES). The system would be dispatchable and reliable, providing both electricity generation and electricity storage services at reduced investment and O\&M cost, due to the use of shared components.

The article presents the layout and numerical models of two different solar-PTES schemes: one in which a conventional CSP plant (based on the steam cycle) is retrofitted with a Brayton heat pump, and another one in which the Brayton cycle is used both during charge and discharge.

The results from the numerical model indicate that, in the two schemes, heat-to-work efficiencies of around $40 \%$ (in CSP operation) and round-trip efficiencies of around 55-60\% (in PTES operation) can be achieved with state-of-the-art components.

Future work will investigate the effect of incorporating cold storage tanks to boost the efficiency of the steam plant within the CSP-retrofit scheme. The sensitivity of the efficiency with the performance of the different components will also be investigated, and thermo-economic and grid-coupling studies will be performed to assess the value that solar-PTES plants can add to the network.

\section{NOMENCLATURE}

Acronyms

$\begin{array}{ll}\text { CAES } & \text { Compressed air energy storage } \\ \text { CSP } & \text { Concentrated solar power } \\ \text { GIES } & \text { Generation-integrated energy storage } \\ \text { HTF } & \text { Heat transfer fluid } \\ \text { LAES } & \text { Liquid air energy storage } \\ \text { LFR } & \text { Linear Fresnel reflectors } \\ \text { O\&M } & \text { Operation and maintenance } \\ \text { PHS } & \text { Pumped hydroelectric storage } \\ \text { PTC } & \text { Parabolic trough collector } \\ \text { PTES } & \text { Pumped thermal energy storage }\end{array}$

Symbols

$c_{p} \quad$ Isobaric specific heat capacity, $[\mathrm{J} / \mathrm{kg} / \mathrm{K}]$

$\epsilon \quad$ Heat exchanger effectiveness

$\eta \quad$ Polytropic efficiency

$h \quad$ Specific enthalpy, $[\mathrm{J} / \mathrm{kg}]$

$\dot{m} \quad$ Mass flow rate, $[\mathrm{kg} / \mathrm{s}]$

$N_{\text {stages }} \quad$ Number of interheated expansions / intercooled compressions

$p \quad$ Pressure, $[\mathrm{Pa}]$

$p_{\max } \quad$ Maximum pressure working fluid, [Pa]

$\dot{Q} \quad$ Heat transfer rate, [W]

$T \quad$ Temperature, $[\mathrm{K}]$

$T_{\text {bot }}, T_{\text {top }}$ Bottom / top temperature of hot stores, [K]

$v \quad$ Specific volume, $\left[\mathrm{m}^{3} / \mathrm{kg}\right]$

$w \quad$ Specific work, $[\mathrm{J} / \mathrm{kg}]$

Subscripts

$0 \quad$ Ambient conditions

c, e Compressor / expander

rev Reversible

\section{FUNDING}

This work is supported in part under the EPSRCfunded Generation Integrated Energy Storage project, number EP/P023320/1.

This work was authored in part by the National Renewable Energy Laboratory, operated by Alliance for Sustainable Energy, LLC, for the U.S. Department of Energy (DOE) under Contract No. DE-AC36-08GO28308. Funding provided by U.S. Department of Energy Office of Energy Efficiency and Renewable Energy Solar Energy Technologies Office. The views expressed in the article do not necessarily represent the views of the DOE or the U.S. Government. The U.S. Government retains and the publisher, by accepting the article for publication, acknowledges that the U.S. Government retains a nonexclusive, paid-up, irrevocable, worldwide license 
to publish or reproduce the published form of this work, or allow others to do so, for U.S. Government purposes.

\section{REFERENCES}

[1] International Energy Agency, "World Energy Outlook 2017," tech. rep., 2017.

[2] H. Chen, T. Cong, W. Yang, C. Tan, Y. Li, and Y. Ding, "Progress in electrical energy storage system: A critical review," Progress in Natural Science, vol. 19, no. 3, pp. 291-312, 2009.

[3] X. Luo, J. Wang, M. Dooner, and J. Clarke, "Overview of current development in electrical energy storage technologies and the application potential in power system operation," Applied Energy, vol. 137, pp. 511536, 2015.

[4] A. Gallo, J. Simões-Moreira, H. Costa, M. Santos, and E. Moutinho dos Santos, "Energy storage in the energy transition context: A technology review," Renewable and Sustainable Energy Reviews, vol. 65, pp. 800822, 2016.

[5] W. D. Steinmann, "Thermo-mechanical concepts for bulk energy storage," Renewable and Sustainable Energy Reviews, vol. 75, no. October 2016, pp. 205-219, 2017.

[6] A. Benato and A. Stoppato, "Pumped Thermal Electricity Storage: A technology overview," Thermal Science and Engineering Progress, vol. 6, pp. 301-315, 2018.

[7] R. E. Morgan, "Liquid air energy storage - from theory to demonstration," International Journal of Environmental Studies, vol. 73, no. 3, pp. 469-480, 2016.

[8] T. Desrues, J. Ruer, P. Marty, and J. F. Fourmigué, "A thermal energy storage process for large scale electric applications," Applied Thermal Engineering, vol. 30, no. 5, pp. 425-432, 2010.

[9] J. Howes, "Concept and development of a pumped heat electricity storage device," Proceedings of the IEEE, vol. 100, no. 2, pp. 493-503, 2012.

[10] A. White, G. Parks, and C. Markides, "Thermodynamic analysis of pumped thermal electricity storage," Applied Thermal Engineering, vol. 53, no. 2, pp. 291-298, 2013.

[11] A. J. White, J. D. McTigue, and C. N. Markides, "Analysis and optimisation of segmented packed-bed thermal reservoirs for electricity storage applications," in Proc IMechE Part A: J Power and Energy, vol. 230, pp. 739-754, 2016.

[12] A. White, J. McTigue, and C. Markides, "Wave propagation and thermodynamic losses in packed-bed thermal reservoirs for energy storage," Applied Energy, vol. 130, pp. 648-657, 2014.

[13] J. McTigue, A. White, and C. Markides, "Parametric studies and optimisation of pumped thermal electricity storage," Applied Energy, vol. 137, pp. 800-811, 2015.

[14] J. McTigue, Analysis and Optimisation of Thermal Energy Storage. $\mathrm{PhD}$ thesis, University of Cambridge, 2016.

[15] J. McTigue and A. White, "A Comparison of Radial-flow and Axial-flow Packed Beds for Thermal Energy Storage," Energy Procedia, vol. 105, no. September 2017, pp. 4192-4197, 2017.

[16] J. D. McTigue, C. N. Markides, and A. J. White, "Performance response of packed-bed thermal storage to cycle duration perturbations," Journal of Energy Storage, vol. 19, no. August, pp. 379-392, 2018.

[17] Newcastle University, "National Facility for Pumped Heat Energy Storage," 2019.

[18] A. Smallbone, V. Jülch, R. Wardle, and A. P. Roskilly, "Levelised Cost of Storage for Pumped Heat Energy Storage in comparison with other energy storage technologies," Energy Conversion and Management, vol. 152, no. May, pp. 221-228, 2017.

[19] R. B. Laughlin, "Pumped thermal grid storage with heat exchange," Journal of Renewable and Sustainable Energy, vol. 9, no. 4, p. 044103 , 2017.

[20] P. Farres-Antunez, "Modelling of Thermal Energy Storage for Bulk Electricity Storage," tech. rep., Cambridge University Engineering Department, Cambridge, 2015.

[21] P. Farres-Antunez and A. White, "Thermodynamic strategies for Pumped Thermal Exergy Storage with liquid reservoirs," in UK Energy Storage Conference, (Birmingham), 2016.

[22] P. Farres-Antunez, H. Xue, and A. J. White, "Thermodynamic analysis and optimisation of a combined liquid air and pumped thermal energy storage cycle," Journal of Energy Storage, vol. 18, no. Offshore Energy Storage, pp. 90-102, 2018.
[23] P. Farres-Antunez, Modelling and development of thermo-mechanical energy storage. $\mathrm{PhD}$ thesis, University of Cambridge, 2018

[24] S. Freund, "Malta PHES. From Powerpoint to Power Plant," in International Workshop on Carnot Batteries, (Stuttgart), 2018.

[25] International Energy Agency, "Technology Roadmap: Solar Thermal Electricity." https://webstore.iea.org/technology-roadmap-solar-thermalelectricity-2014, 2014. Accessed: 2019-05-22.

[26] A. G. Fernández, J. Gomez-Vidal, E. Oró, A. Kruizenga, A. Solé, and L. F. Cabeza, "Mainstreaming commercial CSP systems: A technology review," Renewable Energy, vol. 140, pp. 152-176, 2019.

[27] P. Gauché, J. Rudman, M. Mabaso, W. A. Landman, T. W. von Backström, and A. C. Brent, "System value and progress of CSP," Solar Energy, vol. 152, pp. 106-139, 2017.

[28] National Renewable Energy Laboratory, "Concentrating Solar Power Projects." https://solarpaces.nrel.gov/, 2019. Accessed: 2019-05-22.

[29] W. H. Stein and R. Buck, "Advanced power cycles for concentrated solar power," Solar Energy, vol. 152, pp. 91-105, 2017.

[30] T. Neises and M. J. Wagner, "Simulation of Direct Steam Power Tower Concentrated Solar Plant," ASME 2012 6th International Conference on Energy Sustainability, p. 499, 2013.

[31] M. Mehos, C. Turchi, J. Vidal, M. Wagner, Z. Ma, C. Ho, W. Kolb, C. Andraka, and A. Kruizenga, "Concentrating Solar Power Gen3 Demonstration Roadmap," in NREL Technical Report, NREL/TP-550067464, 2017.

[32] M. Mehos, C. Turchi, J. Jorgenson, P. Denholm, C. Ho, and K. Armijo, "On the path of SunShot: Advancing Concentrating Solar Power Technology, Performance, and Dispatchability," in NREL Technical Report, NREL/TP-5500-65688, pp. 1-66, 2016.

[33] NASA Langley Research Center POWER Project, "POWER Data Access Viewer," 2019.

[34] P. Vinnemeier, M. Wirsum, D. Malpiece, and R. Bove, "Integration of heat pumps into thermal plants for creation of large-scale electricity storage capacities," Applied Energy, vol. 184, pp. 506-522, 2016.

[35] I. Bell, J. Wronski, S. Quoilin, and V. Lemort, "Pure and pseudopure fluid thermophysical property evaluation and the open-source thermophysical property library coolprop," Industrial and Engineering Chemistry Research, vol. 53, no. 6, pp. 2498-2508, 2014.

[36] H. Dixon, Fluid Mechanics and Thermodynamics of Turbomachinery (6th Edition). Elsevier, nov 2010.

[37] F. Incropera, D. DeWitt, T. Bergman, and A. Lavine, Fundamentals of Heat and Mass Transfer. John Wiley and Sons, 7th ed., 2011.

[38] S. Baek, J. H. Kim, S. Jeong, and J. Jung, "Development of highly effective cryogenic printed circuit heat exchanger (PCHE) with low axial conduction," Cryogenics, vol. 52, no. 7-9, pp. 366-374, 2012.

[39] M. Moran and H. Shapiro, Fundamentals of Engineering Thermodynamics. Wiley, 5th ed., 2006. 